\title{
Empirical-Analytical Modelling of the Thermal Performance of a PEMFC-based CHP System
}

\author{
F.J. Asensio ${ }^{1}$, J.I. San Martín ${ }^{1}$, I. Zamora², G. Saldaña ${ }^{1}$, and I. Martín ${ }^{3}$. \\ ${ }^{1}$ Department of Electrical Engineering \\ ${ }^{3}$ Department of Graphic Expression and Engineering Projects \\ Engineering School of Gipuzkoa (Section of Eibar), University of the Basque Country (UPV/EHU) \\ Campus of Gipuzkoa, 20600 Eibar (Spain) \\ Phone number: +0034 943 033010, e-mail: joseignacio.sanmartín@ehu.eus \\ 2 Department of Electrical Engineering \\ Engineering School of Bilbao, University of the Basque Country (UPV/EHU) \\ Campus of Biscay, 48013 Bilbao (Spain) \\ Phone number: +0034946 014063, e-mail: inmaculada.zamora@ehu.eus
}

\begin{abstract}
This paper focuses on the thermal modelling of a CHP system based on Proton Exchange Membrane Fuel Cell (PEMFC) by experimental analysis and analytical relationships. To this end, there have been carried out several experimental tests on a PEMFC $600 \mathrm{~W}$ of electrical power in order to obtain the necessary data for thermal modelling and its subsequent validation. Once made the experimental analysis, data obtained have been used to develop the thermal model of the stack of the fuel cell as well as the entire temperature management system, by implementing various analytical relationships in the MATLAB/Simulink environment.
\end{abstract}

The model obtained has allowed to characterize the thermal behaviour of the fuel cell to different profiles of electrical and thermal energy demand, with a minimum and maximum relative error in the temperature of the stack of $3.77 \%$ and $11.05 \%$, respectively.

\section{Key words}

Proton Exchange Membrane Fuel Cell (PEMFC); Combined Heat and Power (CHP); Empirical Modelling; Thermal Performance.

\section{Introduction}

Fuel cells, as distributed generation system, offer many benefits due to its high overall efficiency, low emissions, low noise and robustness. However, when integrating them into buildings for energy supplying, it is necessary to develop a strategy to maximize the system efficiency, which in turn will be determined by the electrical and thermal demand profiles [1].

The development of reliable models of this type of systems becomes vital when it comes to improving the performance of them, and when testing different control strategies, in order to maximize the overall system efficiency [2], [3].
In the current literature, several methods for modelling PEMFCs can be found. However, most focus on the electrical characteristics, and the temperature is regarded as an input variable to the model instead of an output variable, which is essential when the PEMFC is going to be integrated in a cogeneration system [4]. The temperature of the stack of a fuel cell is closely linked to the rate of catalytic reactions as well as to the humidification of the membrane, which in turn directly affects the efficiency of the fuel cell [5]. In this context, a model that contemplates the thermal behaviour of a fuel cell, will allow to study the effect of the variations of temperature of the stack on the overall efficiency of the fuel cell.

In this sense, in this paper the methodology to develop a thermal model of a PEMFC is shown, so that it can be seamlessly integrated with any other electrical model, resulting in a model that includes the electrical as well as the thermal behaviour, allowing the use thereof in a wide range of simulating scenarios.

\section{Description of HP600 System}

Figure 1 shows the HP 600 system, which is a PEMFC CHP-based system of $600 \mathrm{~W}$ of electrical power.

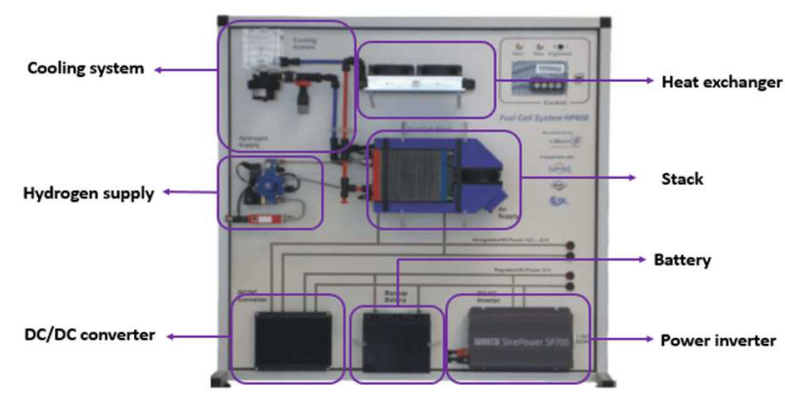

Fig. 1. HP600 PEMFC-based CHP system [6]. 
The HP 600 system consists of a $600 \mathrm{~W}$ stack of 24 cells, an air blower, a cooling system and a power conditioning system. The cooling system consists of a water tank, water pump, and a heat exchanger cooled by forced convection. The power conditioning system consists of a DC / DC converter, a lead-acid battery and a power inverter.

Table I shows the main characteristics of the HP600 PEMFC system.

Table I. - HP600 PEMFC system technical data.

\begin{tabular}{|c|c|c|c|}
\hline \multicolumn{2}{|c|}{ PEM Type ( 24 cells) } & \multicolumn{2}{|c|}{ DC/DC Converter } \\
\hline Rated net power & $600 \mathrm{~W}$ & Nominal output voltage & $12 \mathrm{VDC}$ \\
\hline DC voltage range & $12-22 \mathrm{~V}$ & Output voltage & $10,5-15$ V DC \\
\hline Rated voltage & 14,4 V DC & Power & $600 \mathrm{~W}$ \\
\hline Rated current & $40 \mathrm{~A}$ & Indigrated charge controller & \\
\hline Rated temperature & $40-60^{\circ} \mathrm{C}$ & \multicolumn{2}{|c|}{ DC/AC Inverter } \\
\hline Pressure & $5-25$ bar & Output voltage & $230 \mathrm{VAC}$ \\
\hline Hydrogen consumption & $7 \mathrm{~N} / / \mathrm{min}$ & Power & $700 \mathrm{~W}$ \\
\hline Purity & $5.0(99,999 \%)$ & \multicolumn{2}{|l|}{ Battery } \\
\hline Air supply & Axial Flow Fan & $\begin{array}{l}\text { Nominal voltage } \\
\end{array}$ & $12 \mathrm{VDC}$ \\
\hline Cooling system & Circulation pump & Capacity & $10 \mathrm{Ah}$ \\
\hline & & Dimension & $1000 \times 1000 \times 400 \mathrm{~mm}$ \\
\hline & $\begin{array}{l}\text { exchanger with } \\
\text { cooling fans }\end{array}$ & $\begin{array}{l}\text { Weight } \\
\text { Operating conditions }\end{array}$ & $35 \mathrm{~kg}$ \\
\hline
\end{tabular}

In order to humidify the membranes of the stack, the hydrogen to be supplied at the anode is mixed together with the water obtained from the reduction reaction produced at the cathode. In this way, the ionic resistance of the membrane is reduced [7]. However, to allow the humidification of the membranes and avoid the degradation of them, it is of highly importance to control the temperature and dissipate the excess of heat through the cooling system [8]. To do that, water is pumped from the water tank into the stack, absorbing heat from it. Then, the heat absorbed by the cooling fluid is rejected into the air through an airfluid heat exchanger, which is cooled by two speedcontrolled fans. Finally, the cooling fluid returns cooled to the water tank. When the speed-controlled fans are off, since the heat dissipated in the air is lower than the heat absorbed from the stack, water warms up until the stack temperature reaches a predefined temperature set-point. From that temperature, speed-controlled fans go into operation to control the temperature of the stack by forced convection to maintain the temperature of the stack at the set-point.

As the demanded power is incremented, more oxygen is needed to complete the chemical reactions. In order to control the oxygen introduced to the stack, an air duct system attached to the stack is used to supply atmospheric oxygen through a filter to the fuel cells. The necessary amount of air depending on the temperature and the relative humidity inside the air supply channel is taken in by means of an electrically regulated fan. Exhaust air leaves the duct system together with the moisture resulting from the produced water through an exhaust opening valve, which is electrically controlled.

The HP600 system allows to demand power in three modes: DC unregulated, DC regulated and AC regulated. To do that, since the electrical power supplied by the stack is unregulated (13.5-22 V range), a buck converter is used to reduce and stabilize the voltage level to $12 \mathrm{~V}$ at the input terminals of the inverter. Moreover, a lead-acid battery is connected between the output terminals of the buck converter and the inverter, whose main function is to give support to start the system and to face the rapid variations of the power demand.

\section{Experimental Analysis}

In order to extract data for the development and validation of the thermal model of the HP600, several laboratory tests have been carried out. In this context, several profiles of electrical and thermal energy have been demanded to the HP600 system. These energy profiles have been demand for different stack temperature set points. During the experimental tests the magnitudes of interest have been recorded, as are the temperature of the stack, the temperature of the cooling fluid at the inlet and outlet of the stack, electrical power demand, heat generated, hydrogen flow, cooling fluid flow, etc.

Figure 2 shows the laboratory test connection scheme.

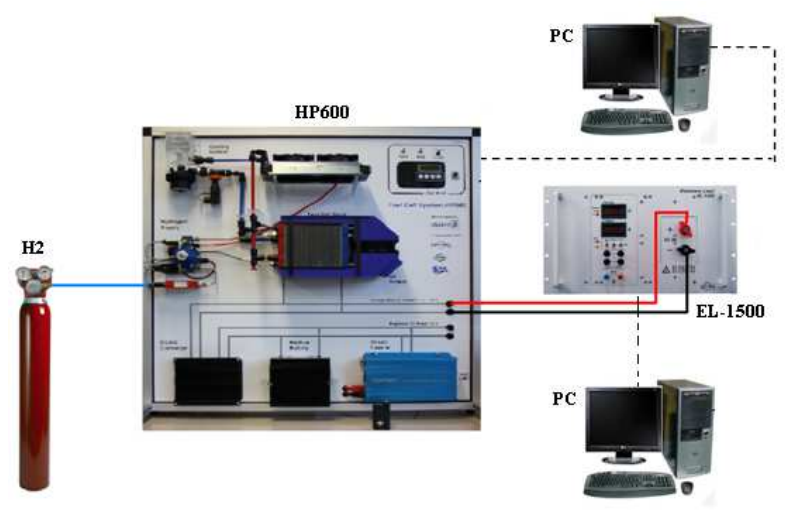

Fig. 2. General test connection scheme.

To demand the electrical power an external electronic load has been connected to the output terminals of the stack. This electronic load has been controlled via PC.

Figure 3 shows the profile of the electric demand and the heat generated by the PEMFC for a temperature set-point of $50^{\circ} \mathrm{C}$. As can be seen, the profile of the electric demand has been performed by increasing the power demand in steps of $150 \mathrm{~W}$, from $150 \mathrm{~W}$ to $550 \mathrm{~W}$.

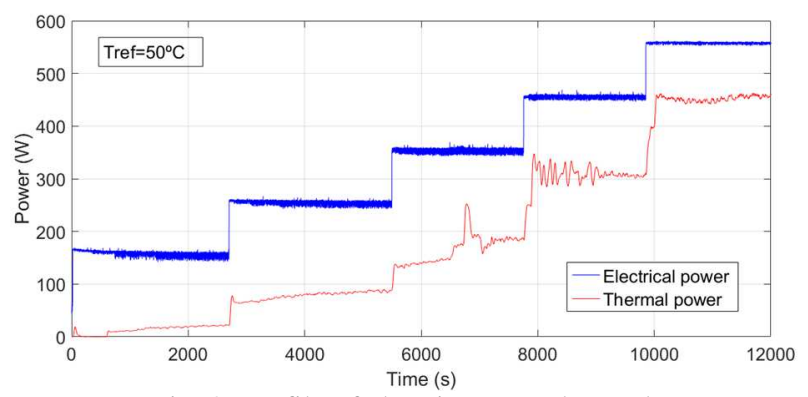

Fig. 3. Profile of electric power demand.

The power demanded at each step has been maintained constant until the temperature of the stack is stabilized, as shown in Figure 4. This way, inertia of the system can be measured for different temperature set-points and different electric power demand. 
Figure 4 shows the temperature of the stack, and the temperatures of the cooling fluid at the inlet and outlet of the stack.
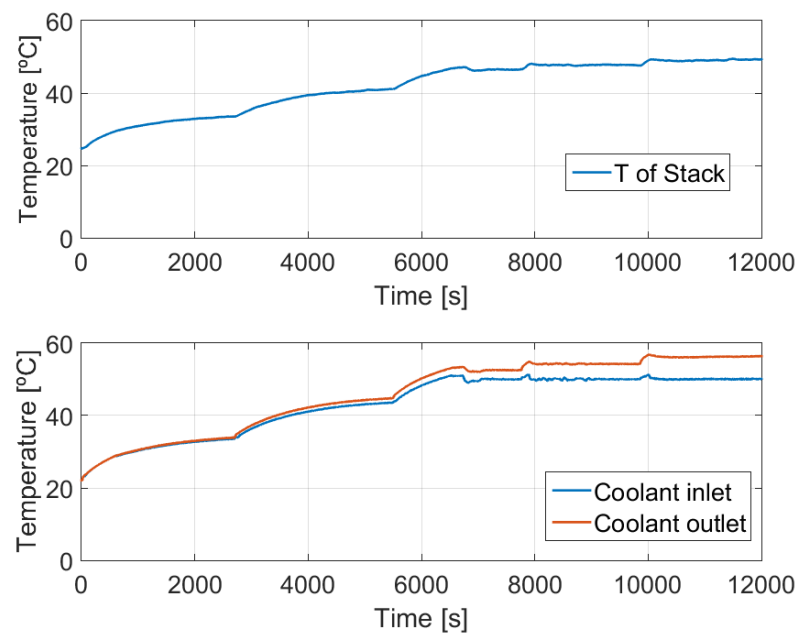

Fig. 4. Temperature of the stack and the coolant at the inlet and outlet of the stack.

The difference in temperature between the inlet and the outlet becomes larger when the temperature set-point of $50^{\circ} \mathrm{C}$ is reached, and the cooling circuit starts extracting heat from the system.

Figure 5 shows the hydrogen flow consumption during the test. As can be seen

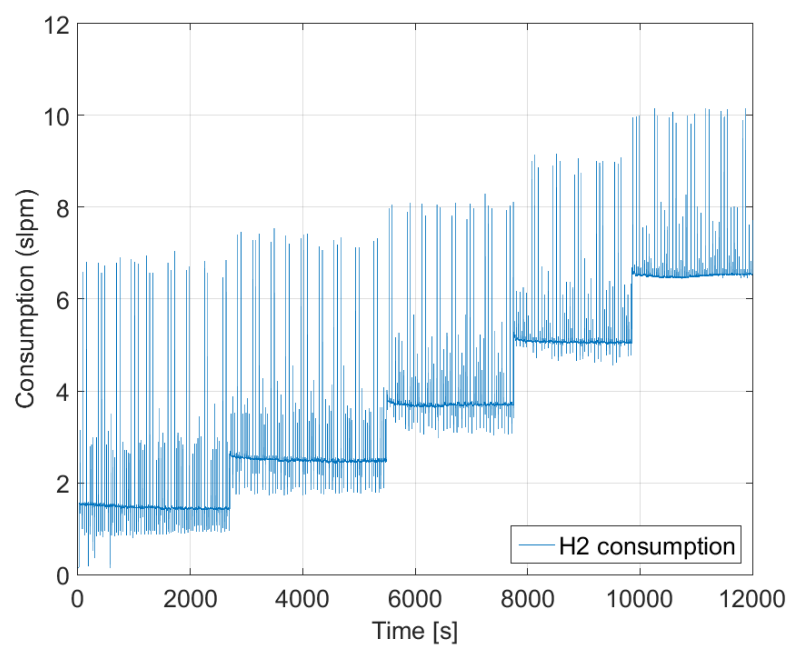

Fig. 5. Hydrogen flow rate during the test.

Several peaks are observed in the hydrogen flow rate due to purging of the excess of water from the stack. These purges are made in order to avoid flooding of the last cells of the stack.

Also, there have been performed measurements with a thermal imaging camera to validate the thermal results. In this context, figure 6 and Figure 7 show the temperature distribution over the entire system and the stack, respectively. As can be observed, the higher temperatures are concentrated in the stack, the water tank and the pipes that connect the stack, and the heat exchanger.

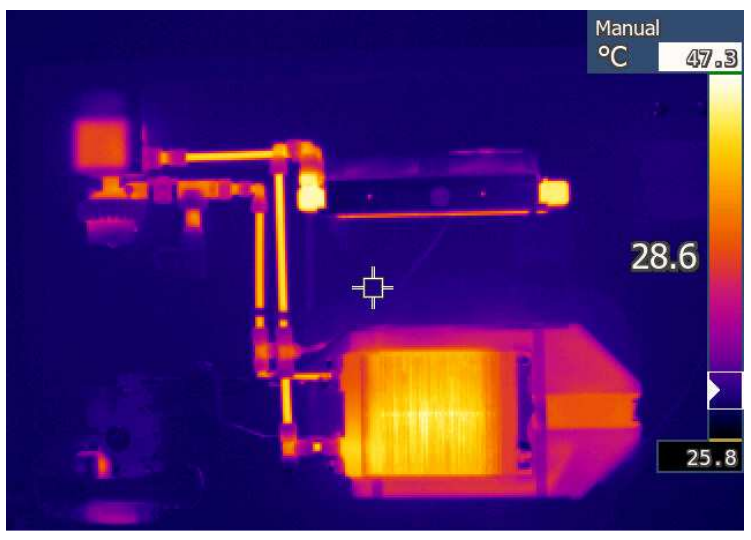

Fig. 6. Temperature distribution over the entire system.

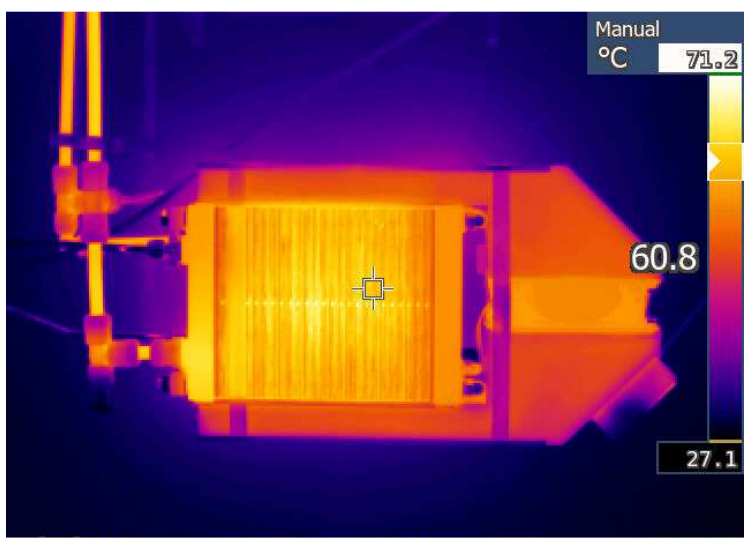

Fig. 7. Temperature distribution over the stack.

Due to its low variation, the cooling fluid flow rate has been considered as a constant ( $11 / \mathrm{min})$.

\section{Thermal Modelling}

Figure 8 shows the overall thermal modelling system, which has been implemented in the MATLAB/Simulink environment. The thermal model is based on (1)-(13) equations described below.

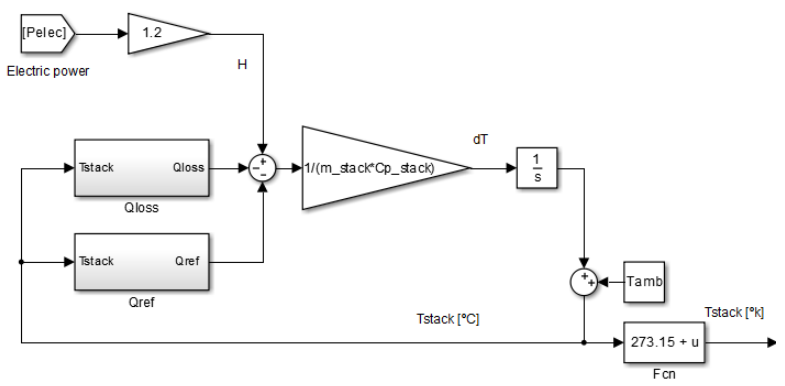

Fig. 8. Thermal model implemented in the MATLAB/Simulink environment.

Thermal modelling is based on an energetic balance, as it is shown in equation (1), given as:

$$
\dot{H}-\dot{Q}_{\text {loss }}-\dot{Q}_{\text {cooling }}=m_{\text {stack }} \cdot c_{p} \cdot \frac{d T_{s}}{d t}
$$


where:

$\dot{\boldsymbol{H}}$ is the total heat power produced in the stack $[W], \dot{Q}_{\text {loss }}$ is the total heat loss due to natural convection and radiation $[W], \dot{Q}_{\text {cooling }}$ is the heat extracted from the stack by the cooling system $[W], m_{\text {stack }}$ is the mass of the stack $[k g], c_{p}$ is the specific heat of the stack $\left[J \cdot \mathrm{kg}^{-1} \cdot \mathrm{K}^{-1}\right]$, and $T_{S}$ is the stack temperature $[K]$.

The total heat produced $\dot{H}$ has been empirically linked to the electrical power generated. The term $\dot{Q}_{\text {loss }}$ has been calculated using the Newton Cooling equation (2) for the natural convection, given as:

$$
\dot{Q}_{l o s s}=h \cdot A_{s} \cdot\left(T_{s}-T_{a}\right)
$$

where:

$h$ is the heat transfer coefficient between the air and the stack surface area $\left[W \cdot m^{-2} \cdot K^{-I}\right], A_{s}$ is the stack surface area $\left[\mathrm{m}^{2}\right]$, and $T_{a}$ is the ambient temperature $[K]$. An empirical vertical isothermal sheet correlation (3) has been used with the purpose of estimating the magnitude of $h$, valid for the entire $R a$ and $P r$ range, given as:

$$
h=\frac{N u s s \cdot K_{\text {air }}}{A l t}
$$

where $\mathrm{K}_{\mathrm{air}}$ is the thermal conductivity of the air $\left[\mathrm{W} \cdot \mathrm{m}^{-1} \cdot \mathrm{K}^{-1}\right]$ and alt is the value of largest dimension of the stack $[\mathrm{m}]$, and Nuss is the number of Nusselt [], which is defined in (4).

$$
\text { Nuss }=0.825+\frac{0.387 \cdot R a^{1 / 6}}{\left(1+(0.492 / P r)^{\frac{9}{16}}\right)^{8 / 27}}
$$

Where $R a$ is Rayleigh number [] and $\operatorname{Pr}$ is Prandtl number []. Rayleigh number is calculated in (5).

$$
R a=\frac{\mathrm{B} \cdot\left(T_{s}-T_{a}\right) \cdot a l t^{3}}{v^{2}} \cdot \operatorname{Pr}
$$

where $v$ is kinematic viscosity $\left[\mathrm{m}^{2} \cdot \mathrm{s}^{-1}\right]$ and $\mathrm{B}$ is the coefficient of thermal expansion $\left[K^{-1}\right]$, which is calculated in (6).

$$
\mathrm{B}=\frac{1}{T_{e v}+273}
$$

$R a$ and $\operatorname{Pr}$ have been considered as an average temperature between the ambient temperature and the temperature of the stack, known as evaluation temperature $T_{e v}$. This temperature is calculated in (7), given as:

$$
T_{e v}=\frac{T_{a}+T_{s}}{2}
$$

In this model, only the frontal side of the stack has been considered. This is because the other sides of the stack are isolated and the heat lost by those sides is very small compared to the heat lost by the front side. This effect can be observed in the thermal image of the figure 7 .

Finally, the term $\dot{Q}_{\text {cooling }}$ has been calculated by equation (8), given as:

$$
\dot{Q}_{\text {cooling }}=\dot{m} \cdot c_{p} \cdot\left(T_{i}-T_{o}\right)
$$

where $\dot{m}$ is the mass flow of the coolant $[\mathrm{kg} / \mathrm{s}], c_{p}$ is the specific heat of the coolant $\left[\mathrm{J} \cdot \mathrm{kg}^{-1} \cdot \mathrm{K}^{-1}\right]$, and $T_{i}$ and $T_{o}$ are the input and output coolant temperatures to the stack $[K]$, respectively.

All variables are fully defined except coolant inlet temperature $\left(T_{o}\right)$. For this, a forced convection correlation has been used, known as temperature increase in contact with a constant temperature surface (9):

$$
T_{o}=T_{s}-\left(T_{s}-T_{i}\right) \cdot e^{\frac{-h_{\text {cooling }} \cdot A_{\text {s cooling }}}{m_{\text {coolant }} \cdot c_{p \text { coolanr }}}}
$$

Dittus-Boelter correlation (10) has been used to determine the value of $h_{\text {coolant }}$ in a turbulent flux and smooth pipes in a similar way to that done in natural convection, valid for entire $R a$ and $P r$ range.

$$
h_{\text {coolant }}=\frac{\text { Nuss }_{\text {coolant }} \cdot K_{\text {coolant }}}{D_{H}}
$$

where $D_{H}$ is the hydraulic diameter of the cooling system pipes, calculated in (11), given as:

$$
D_{H}=\frac{4 \cdot A}{P}
$$

where $A$ is the equivalent section area of the cooling system pipes $\left[\mathrm{m}^{2}\right]$ and $P$ is the equivalent perimeter of these $[m]$.

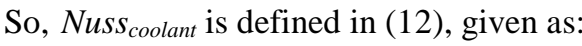

$$
\text { Nuss }_{\text {coolant }}=0.023 \cdot R \mathrm{e}^{0.8} \cdot \operatorname{Pr}_{\text {coolant }}^{0.4}
$$

where, $R e$ is Reynolds number []. In this case, Prandtl number, $P r_{\text {coolant }}$, is calculated as follows:

$$
P r_{\text {coolant }}=\frac{v_{\text {coolant }}}{\alpha}=\frac{C_{\text {Pcoolant }} \cdot \mu_{\text {coolant }}}{K_{\text {coolant }}}
$$

Since the cooling system is a closed circuit, $T_{i}$ has been defined according to $T_{o}$ value. For this, taking into account that the real system uses a heat exchanger to dissipate the heat absorbed by the coolant from the stack, a heat exchanger has been modelled and simulated assuming the difference between the real temperature of the stack and the set point temperature. This difference has been taken into account as an error in a close loop control, and it has been used to implement a PID controller aimed at regulating the amount of heat that has to be extracted from the stack to maintain the temperature of the stack below the set-point temperature. Table II shows all the 
parameters used to implement the model in the MATLAB/Simulink environment.

Table II. Model parameters.

\begin{tabular}{|c|c|c|c|c|c|}
\hline \multicolumn{3}{|c|}{ Water (Coolant) } & \multicolumn{3}{|c|}{ Air } \\
\hline Q & Flux & $11 / \min$ & Ta & Air's temperature & $23{ }^{\circ} \mathrm{C}$ \\
\hline$\rho$ & Density & $1000 \mathrm{Kg} / \mathrm{m}^{3}$ & $Q$ & Flux & $0.04 \mathrm{Kg} / \mathrm{s}$ \\
\hline Cp & Specific Heat & $4180 \mathrm{~J} /(\mathrm{Kg} \cdot \mathrm{K})$ & Cp & Specific Heat & $1000 \mathrm{~J} /(\mathrm{Kg} \cdot \mathrm{K})$ \\
\hline m & Dynamic viscosity & $\begin{array}{c}0.467^{*} 10^{\wedge}-3 \\
\mathrm{~kg} /(\mathrm{m} \cdot \mathrm{s})\end{array}$ & Pr & Pranditl & 0.7309 \\
\hline Pr & Prandtl & 2.99 & v & Kinematic viscosity & $1.516 * 10 \mathrm{c}-5 \mathrm{~m}^{2} / \mathrm{s}$ \\
\hline K & Thermal consuctivity & $0.654 \mathrm{~W} /\left(\mathrm{m}^{*} \mathrm{~K}\right)$ & $\mathbf{K}$ & Thermal consuctivity & $\begin{array}{c}0.02514 \\
\mathrm{~W} /\left(\mathrm{m}^{*} \mathrm{~K}\right)\end{array}$ \\
\hline \multicolumn{6}{|c|}{ Stack } \\
\hline $\mathbf{m}$ & Mass & & \multicolumn{3}{|c|}{$20 \mathrm{Kg}$} \\
\hline$\rho$ & Density & & \multicolumn{3}{|c|}{$2150 \mathrm{Kg} / \mathrm{m} 3$} \\
\hline Cp & Specific Heat & & \multicolumn{3}{|c|}{$710 \mathrm{~J} /(\mathrm{Kg} \cdot \mathrm{K})$} \\
\hline
\end{tabular}

\section{Simulation Results}

Following simulation results correspond to the case in which the set-point temperature has been kept at the temperature of $50^{\circ} \mathrm{C}$.

Figure 9 shows the real and simulated coolant inlet and outlet temperatures evolution over time.
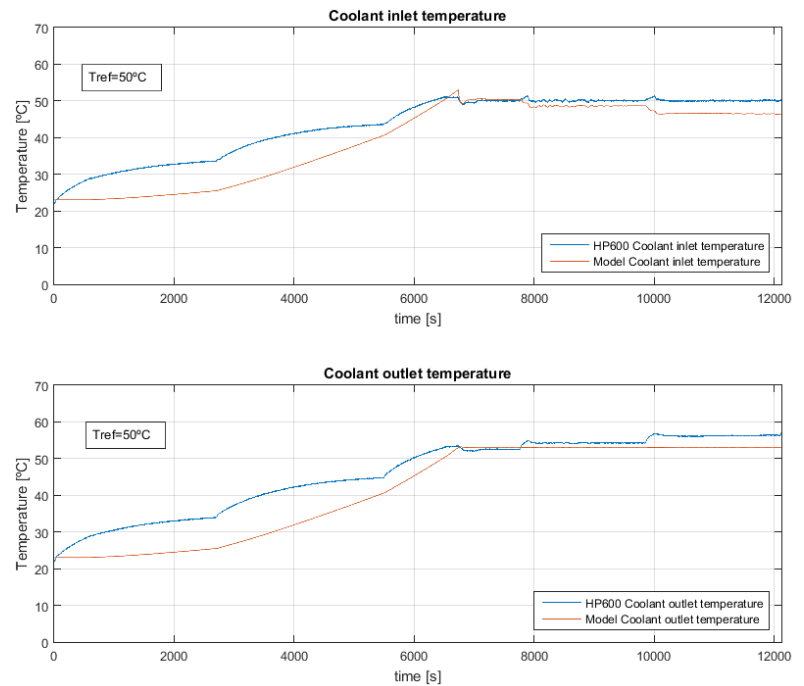

Fig 9. Real and simulated coolant inlet and outlet temperatures evolution over time

As can be observed in figure 9, the error between the real and simulated temperatures becomes smaller when the setpoint temperature is reached.

As can be seen, the model could be improved for a better adjustment between the real and simulated temperatures. of the temperatures to the real temperatures. The temperature deviation between the real and simulated temperatures is due to the control of the speed-controlled fans of the cooling circuit. In this sense, in the real system, the cooling system starts to act before the temperature set point is reached. In the model, in contrast, heat removing is applied when temperature regulation is needed only. That is, in the model heat is extracted only when the set-point temperature is reached.

Figure 10 shows the real and simulated stack temperature evolution, for a cooling temperature set point of $53{ }^{\circ} \mathrm{C}$.

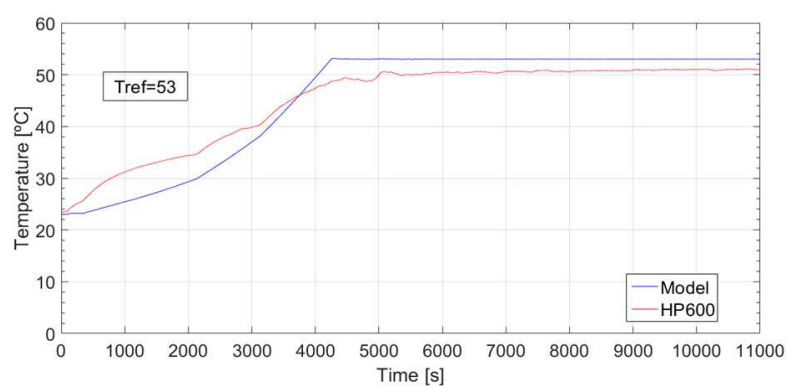

Fig. 10. Real and simulated stack temperature evolution.

At nominal power in steady state $96.23 \%$ of accuracy is reached. As the demanded power decreases the accuracy falls to a minimum of $88.95 \%$. In this sense, it has to be noted that the model has been developed taking into account the nominal operating conditions. Therefore, the accuracy falls when the PEMFC does not operate at the nominal operating point, where the ratio of electrical to thermal energy is not so strict. On the other hand, when calculating the losses to the environment, neither the external surfaces of the cooling circuit pipes nor some sides of the stack have been taken into account. This all result in a lower accuracy of the model.

In order to study the effect of the temperature on the hydrogen consumption, the thermal model developed has been integrated with the PEMFC model provided in MATLAB/Simulink. The model provided in Simulink does not calculate the temperature of the stack but offers the option of taking it into account as an input variable. This aspect has allowed to link the thermal model to the model provided in MATLAB. This model has been configured according the instructions given in MATLAB to emulate the performance of the HP600.The electrical demand profile used in this simulation has been the profile shown in figure 3 . Figure 11 shows the integration of the thermal model developed together with the user defined electrical model.

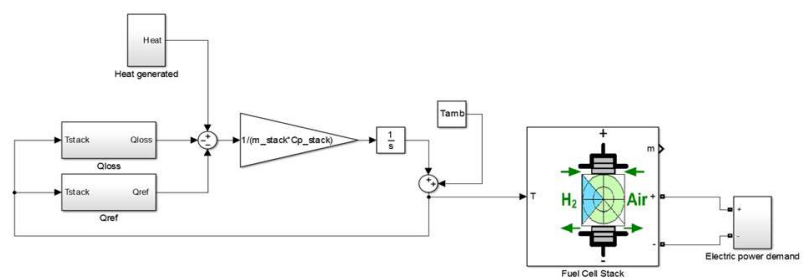

Fig. 11. Thermal model developed integrated with the electric model provided in MATLAB/Simulink environment.

Figure 12 shows the hydrogen flow rate of the PEMFC with and without taking into account the temperature variation of the stack.

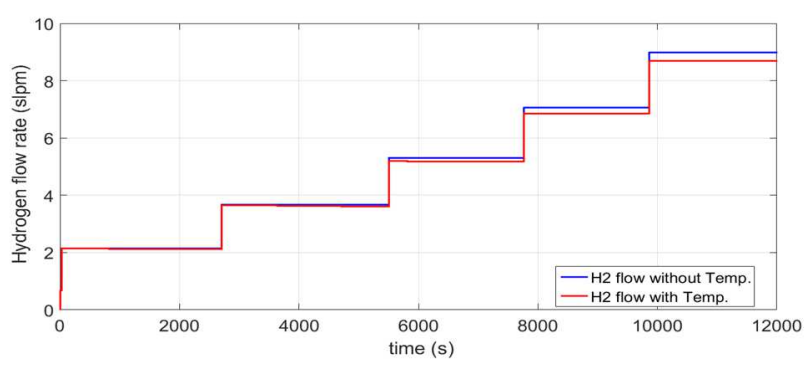

Fig. 12. Thermal model developed integrated with the electric model provided in MATLAB/Simulink environment. 
As can be observed in figure 12, for the case in which the temperature is taken into account, the hydrogen flow rate is slightly lower than in the case in which the temperature is not considered. Furthermore, it can be shown how the difference is greater as the stack temperature increases. The maximum hydrogen flow rate difference obtained between the two simulated variables has been $0.3 \mathrm{slpm}$. It has to be noted that the real hydrogen flowrate at nominal operating point has been 8.7 slpm, which has been the same flow rate that the obtained by the model obtained as a result of the integration of the two models.

\section{Conclusions}

This paper has presented a model that can reproduce the thermal dynamics of a $600 \mathrm{~W}$ PEMFC-based CHP system. The accuracy of the model has been up $96.23 \%$ at nominal power, but is slightly reduced as we move away from this operating point. This is because the model uses a stack temperature control that begins to act once the temperature has reached the reference set point, while the actual system anticipates this situation with an analogue and gradual control of the cooling system, removing heat from the stack before its temperature reaches the set point value.

The model developed and the methodology presented for obtaining it, is a useful tool when developing control strategies that consider the temperature of the stack to prioritize the thermal efficiency versus the electrical efficiency or vice versa, depending on the situation and the energy demand.

It has been shown how the accuracy of a model that does not calculate the system temperature can be improved by integrating it with the model proposed in this paper. In this sense, the developed thermal model has been integrated with the model provided in MATLAB, resulting in an accuracy improvement of $3.45 \%$ when simulating the hydrogen flow consumed.

\section{Acknowledgement}

The authors acknowledge the financial support from the University of the Basque Country UPV/EHU (project EHU13/66).

\section{References}

[1] A. Adama, E. S. Fragab, and D. J.L. Bretta. "Options for residential building services design using fuel cell based microCHP and the potential for heat integration", Applied Energy (2015), Vol. 138, pp. 685-694.

[2] A. Salva, A. Iranzo, F. Rosa, E. Tapia, E. López, and F. Isorna, "Optimization of a PEM fuel cell operating conditions: Obtaining the maximum performance polarization curve", International Journal of Hydrogen Energy (2016), Vol. 41, pp. 19.713-19.723.

[3] B. Najafi, A. H. Mamaghani, F. Rinaldi, and A. Casalegno, "Long-term performance analysis of an HT-PEM fuel cell based micro-CHP system: Operational strategies", Applied Energy (2015), Vol. 147, pp. 582-592.

[4] S. Ham, S. Jo, H. Dong, and J. Jeong, "A simplified PEM fuel cell model for building cogeneration applications", Energy and Buildings (2015), Vol. 107, pp. 213-225.

[5] K. Scott, C. Xu, and X. Wu, "Intermediate temperature protonconducting membrane electrolytes for fuel cells" Wiley, Energy and Environment (2014), Vol. 4, pp. 24-41.
[6] HP600 Fuel Cell System User's Manual.

[7] M.R. Molavian, A. Abdolmaleki, and K. Eskandari, "Theoretical investigation of proton-transfer in different membranes for PEMFC applications in low humidity conditions", Journal of Power Sources (2016), Vol. 122, pp. 126138.

[8] C.M. Branco, S. Sharma, M.M.C. Forte, and R. SteinbergerWilckens, "New approaches towards novel composite and multilayer membranes for intermediate temperature-polymer electrolyte fuel cells and direct methanol fuel cells", Journal of Power Sources (2016), Vol. 316, pp. 139-159. 